\title{
La competencia literaria y comunicativa en la formación inicial del docente. Presentación de una experiencia
}

\section{The Literary and communication competence to the initial training teacher. Presentation of an experience}

\author{
Eloísa Reche Urbano ${ }^{1}$, María Amor Martín Fernández ${ }^{2}$, María Josefa Vilches Vilela ${ }^{3}$ \\ ${ }^{1}$ Departamento Educación, Centro de Magisterio Sagrado Corazón, Universidad de Córdoba, España (fe1reure@uco.es) \\ ${ }^{2}$ Departamento Filología, Centro de Magisterio Sagrado Corazón, Universidad de Córdoba, España (fe1mafem@uco.es) \\ ${ }^{3}$ Departamento Educación, Centro de Magisterio Sagrado Corazón, Universidad de Córdoba, España (fe1vivim@uco.es)
}

Recibido el 13 de noviembre de 2016; revisado el 24 de noviembre de 2016; aceptado el 24 de noviembre de 2016; publicado el 2 de diciembre de 2016

\section{RESUMEN:}

La competencia comunicativa es un elemento fundamental en la formación de los futuros profesionales de la docencia y esta debe ser trabajada de manera transversal desde las diversas materias que conforman los planes de estudios, especialmente, en aquellas en las que el alumnado deba desarrollar conocimientos, habilidades y destrezas asociadas a ella. En esta línea, surge la experiencia de innovación educativa basada en modulación de las metodologías que han permitido la coordinación interdisciplinar, en el curso académico 2014-2015, de las asignaturas "Formación literaria y Literatura infantil" y "Educación Mediática y aplicaciones didácticas de las TIC", que se imparten en segundo curso del Grado en Educación Primaria, en el Centro de Magisterio Sagrado Corazón (Universidad de Córdoba). Se diseñó una práctica de narrativa audiovisual, cuyo punto de partida fue la selección de las competencias y la formulación de los objetivos a alcanzar. Teniendo en cuenta la interactuación interacción de los diversos aprendizajes adquiridos por el alumnado en las distintas materias, se planificaron las metodologías, la secuenciación y la temporalización de las diversas fases de la práctica, así como la guía y los instrumentos de evaluación, tanto del logro de las competencias como de la satisfacción del alumnado con la experiencia. Los resultados obtenidos evidencian que la realización de este tipo de prácticas coordinadas favorece la adquisición y movilización de las competencias asociadas al Título.

$\begin{array}{lr}\text { PALABRAS CLAVE: } & \text { COMPETENCIA } \\ \text { COMUNICATIVA, } & \text { COMPETENCIA } \\ \text { MEDIÁTICA, ENSEÑANZA } & \text { SUPERIOR, } \\ \text { INNOVACIÓN EDUCATIVA. } & \end{array}$

\section{ABSTRACT:}

Communicative competence is a key element for future professionals of teaching training and this must be worked transversely from the different subjects that make up the curriculum, especially in those in which students must develop knowledge, skills and abilities associated with it. In this context, the innovation educational experience based on a modulation of methodologies that this has allowed the interdisciplinary coordination of "Literary training and children's literature" and "Media education and teaching applications of ICT" subjects that are given in the second year to students studying towards a Primary Education Degree at the Teacher Training College Sagrado Corazón (Córdoba University), in the 2014-2015 academic year. An audiovisual narrative exercise was designed, whose starting point was the selection of competence and formulation of objectives to achieve. Considering the interaction of the different learning skills acquired by students in the diverse subjects, they were planned the methodologies, sequencing and scheduling of the different phases of the exercise, as well as the guide notes and the evaluation 
instruments, both from the skills acquisition and from the student's satisfaction with the experience. The obtained results show that the implementation of such coordinated methodological practices favours the acquisition and mobilization of skills associated with academic qualification.

KEYWORDS:

COMMUNICATIVE COMPETENCE, MEDIA LITERACY, HIGHER EDUCATION, EDUCATIONAL INNOVATION.

\section{INTRODUCCIÓN}

La innovación educativa es uno de los aspectos claves para llevar a cabo el diseño de estrategias de enseñanza-aprendizaje, que propicien la formación en competencias profesionales del alumnado universitario. Se entiende por innovación educativa la adopción de prácticas novedosas que se adapten a las nuevas formas de entender el aprendizaje y, en consecuencia, los diversos modos de enseñanza y la evaluación de los resultados de este tipo de proceso formativo.

El ámbito educativo ha experimentado, en los últimos tiempos, cambios sustanciales en la manera de enfocar las metodologías. Ha dirigido la mirada a contextos o escenarios en los que el discente no solo realice una mera asimilación de contenidos, sino que sea capaz de adquirir saberes, movilizarlos según las necesidades y mostrarse como persona autónoma, reflexiva y emprendedora, facetas que contribuirán a su desarrollo personal y que la sociedad actual demanda en todos los sectores (Imaz, 2015; Vázquez, 2015). Se habla de formación en competencias y esta es una realidad cuando el diseño de la práctica educativa se realiza con la finalidad de lograr la capacitación del alumnado en conocimientos, destrezas y actitudes que lo acrediten para el desempeño eficiente de su labor profesional y descansa "en la organización de las actividades de enseñanza y aprendizaje, en los papeles respectivos de los profesores y de los estudiantes y en la evaluación de los aprendizajes" (Fernández, 2010, p. 14).

A su vez, esta forma de ver la docencia y, en consecuencia, el aprendizaje, deben ir acompañados de fórmulas eficaces que permitan valorar los diversos aspectos que desarrolla el alumnado. Por tanto, la evaluación de la actividad pasa de los criterios meramente conceptuales a indicadores de saberes, destrezas-habilidades y actitudes del estudiante, en función del contexto en el cual se realiza la práctica o su utilidad.

Ante un modelo de enseñanza-aprendizaje enmarcado en las directrices del Espacio Europeo de Educación Superior (EEES), las estrategias pedagógicas deben modularse dependiendo de las necesidades de formación del alumnado, han de ser flexibles e integradoras, favorecer una atención personalizada, a tenor de las capacidades y habilidades iniciales, así como los ritmos de aprendizaje.

El profesorado tiene ante sí nuevos retos que se podrían concretar en: 1) afrontar la diversidad del alumnado universitario; 2) el acompañarle en sus procesos de aprendizaje, y 3) el facilitarle un desarrollo integral que le prepare para la vida. (Álvarez, 2008, p. 73).

Desde esta perspectiva, la reorganización del escenario formativo hacia modelos más afines requiere cambios metodológicos, que surgen como respuesta a estas demandas de los propios estudiantes; pero para ello, los docentes deben encaminar su planificación a la renovación de sus prácticas. La innovación educativa con metodologías emergentes implica la adaptación de modelos más interactivos que ayuden al alumnado en las diferentes fases del aprendizaje. La combinación de diversos métodos permite la flexibilidad en los modos y tiempos de aprendizaje.

Lo que se pretende en el nuevo sistema educativo es, precisamente, capacitar a los estudiantes para que utilicen con mayor amplitud y seguridad los conocimientos que reciban. Un mayor dominio de competencias en conceptos centrales puede llevar consigo una disminución en información no esencial o complementaria (Mayorga y Madrid, 2010, p. 92).

En esta línea surge la experiencia que se describe. Se centra en la formación y evaluación del logro de competencias comunicativas a través de la formación literaria y la alfabetización mediática (audiovisual), concebidas como factor clave para el desarrollo profesional del alumnado del Grado en Educación Primaria. El maestro y la maestra son profesionales de la comunicación, por cuanto el proceso de enseñanza-aprendizaje es por sí mismo un acto de comunicación y porque han de ser capaces de utilizar todos los medios a su alcance para informar, comunicar, transmitir, motivar e incentivar a su alumnado. 


\section{FORMACIÓN LITERARIA Y LA ALFABETIZACIÓN AUDIOVISUAL EN EL MARCO DE LA COMPETENICA COMUNICATIVA}

Uno de los objetivos fundamentales de la formación de los futuros maestros y maestras es la adquisición de la competencia comunicativa, para ellos mismos y para poder lograrla en su alumnado. Es entendida, según los presupuestos de Gumperz y Hymes (1972) y las aportaciones de Canale (1999) y Lomas (2010), como la capacidad para "comunicarse de manera eficaz en contextos culturalmente significantes" ( $p$. 32). Este último autor considera que "la competencia comunicativa es el eje pedagógico desde el que conviene articular la educación lingüística y literaria" (p. 32).

Además, la competencia comunicativa se completa con el desarrollo de la competencia literaria, que consigue "activar aquellas virtualidades significativas que los textos literarios aportan, como situación discursiva específica para el desarrollo de la competencia comunicativa en general" (Mendoza, 2008, p. 305). En este sentido, la comunicación literaria procede de una voluntad artística, tiene una finalidad estética, posee como herramienta la palabra experta y produce textos de alta calidad y belleza. La educación literaria, por tanto, amplía los conocimientos linguísticos, dota de destrezas en el uso de la palabra y de los recursos retóricos, ayuda al análisis y compresión de textos, provoca la imaginación y fomenta la creatividad. Sin embargo, no es fácil su logro y para ello hay que "hacer experimentar la comunicación literaria [...]. Esto implica crear situaciones que permitan percibir la literatura como situación de comunicación y como hecho cultural compartido" (Mendoza, 2008, p. 19).

A su vez, las nuevas formas de interacción y espacios comunicativos han provocado cambios importantes en las formas mismas de expresión.

En la actualidad, dicha comunicación entraña un complejo proceso en que los códigos verbales estrictamente lingüísticos han dejado de desempeñar el papel exclusivo en el discurso y comparten su valor en la construcción del sentido con otros códigos no verbales, especialmente icónicos y multimedia, que precisan de los hablantes estrategias específicas para su adecuado uso e interpretación sémica. (Prado, 2001, p. 22).

La sociedad tiene otros escenarios de interacción, derivados de la tecnología, que modulan la forma de comunicación a través de nuevos modos, códigos, soportes de información y comunicación en continua renovación. Este hecho cambia el paradigma de alfabetización, que más allá de la capacidad y habilidad que tiene una persona para leer y escribir, se centra en la formación, en la competencia comunicativa y social, la cual conjuga la palabra, la imagen y el sonido, teniendo en cuenta el contexto de comunicación, cultural e interpersonal, en el que se produce (Rodríguez, 2004).

Asociada a la competencia comunicativa se encuentra la competencia audiovisual, centrada en los conocimientos, habilidades y actitudes relacionadas con los medios de comunicación de masas y el lenguaje audiovisual (Pérez y Delgado, 2012). Esta, a través de los elementos sonoros y de los elementos visuales en combinación simbiótica, contribuye a la transmisión de la información. Una imagen, acompañada de sonido (música), puede tener un sentido determinado y, sin embargo, esa misma imagen, combinada con texto adopta un significado diferente, quedando su interpretación, en ambos casos, a merced del espectador en función de sus experiencias, pensamientos, sensibilidad, etc. En la narrativa audiovisual, la imagen no es solo una apariencia, sino el contenido humano que hay vertido en ella, a través de la conjunción de los diversos aspectos morfológicos, sintácticos, semánticos y, como no, estéticos que el autor utilice (Gómez Tarín, 2011).

La imagen, como la belleza del rostro, se constituye de dentro afuera, por su poder expresivo. Una imagen es más que una figura, tiene profundidad. La figura es plana, es lo que queda de la imagen cuando se independiza su apariencia sensible. [...]. En una imagen se expresa algo metasensible: una idea, un valor, un sentimiento. Por su expresividad de lo profundo e íntimo la imagen es un lenguaje que colabora a crear ámbitos (Muñoz, 2003, p. 133).

El gran poder comunicador de la narrativa audiovisual estriba en la pluralidad de sentidos que moviliza. Cuando se habla de imagen suele entenderse como un elemento de representación de la realidad, pero según del contexto en la que se utilice y la combinación de los elementos que la conforman, imagen-sonido-palabra, se puede utilizar para "informar, para crear, expresar o comunicar, para persuadir y seducir, para convencer y verificar, para deleitar, para infundir temor o seguridad, para servir como instrumento ideológico, o como arma arrojadiza para exhortar, para evocar o incluso para exorcizar" (Gómez Isla, 2013, p. 10).

Por otro lado, en el ámbito educativo, la competencia audiovisual atiende a la capacidad de un individuo para interpretar y analizar desde la reflexión crítica las imágenes y los mensajes audiovisuales y para expresarse con una mínima 
corrección en el ámbito educativo. Esta competencia está relacionada con el conocimiento de los medios de comunicación y con el uso básico de las tecnologías multimedia necesarias para producirlas (Ferrés, 2007).

Por su parte, la Ley Orgánica 8/2013 para la mejora de la Calidad de la Enseñanza y, en concreto, el Real Decreto 216/2014, por el que se establece el currículo básico de la Educación Primaria y la Orden de 17 de marzo de 2015, por la que se desarrolla el currículo correspondiente a la Educación Primaria en Andalucía, contemplan en dos de sus áreas los aspectos que se han ido mencionando.

El área de Lengua castellana y Literatura tiene como finalidad el desarrollo de la competencia comunicativa del alumnado en su dimensión pragmática, lingüística, sociolingüística y literaria, que le permita desenvolverse de manera eficaz en cualquier situación comunicativa de la vida familiar, social y profesional. A su vez, pretende el aprendizaje progresivo de las habilidades lingüísticas básicas y la adquisición de competencias "en los usos discursivos del lenguaje a partir del conocimiento y la reflexión necesarios para apropiarse de las reglas gramaticales y ortográficas, imprescindibles, para hablar, leer y escribir correctamente en todas las esferas de la vida" (Real Decreto 126/2014, p. 19379).

Por otro lado, el aprendizaje literario además de enseñar la expresividad de la lengua en toda su extensión y belleza, "desarrolla la capacidad crítica y creativa del alumnado, le da acceso al conocimiento de otras épocas y culturas y le enfrenta a situaciones que enriquecen su experiencia del mundo y favorecen el conocimiento de uno mismo" (Real Decreto 126/2014, p. 19378).

En el área de Educación Artística, el primero de los bloques de la Educación Plástica, denominado Educación Audiovisual, está dirigido al estudio de la imagen en todas sus manifestaciones, tanto visual como audiovisual, en el que cobran una gran relevancia las aportaciones que las Tecnologías de la Información y la Comunicación realizan al mundo de la imagen (Real Decreto 126/2014, p. 19401).

\section{DESARROLLO DE LA EXPERIENCIA}

\subsection{Objetivos del proyecto Háblame de Córdoba}

Esta práctica se ubica en el contexto de las asignaturas "Formación literaria y Literatura infantil" (materia de 6 créditos) y "Educación Mediática y aplicaciones didácticas de las TIC" (4 créditos), que se imparten en el segundo curso del
Grado en Educación Primaria. El objetivo general de la misma es que el alumnado participante adquiera las competencias comunicativa, literaria y audiovisual, siendo el punto de partida la elaboración de un guion literario y su correspondiente guion técnico de una narrativa audiovisual, que muestre Córdoba al alumnado de la etapa de Educación Primaria, a través de la visión del docente.

Las características del trabajo solicitado fueron:

- Práctica de carácter individual.

- Texto de elaboración propia y original.

- Montaje audiovisual de 25 fotogramas (máximo) y con una limitación de peso de 80 $\mathrm{MB}$, limitación condicionada por el modo de entrega: subida a una tarea creada en la plataforma UcoMoodle.

- La estructura del trabajo: portada, desarrollo de la narración, mapa de recorrido y contraportada.

La batería de competencias y resultados de aprendizaje seleccionados de ambas materias y que el estudiante adquiere en ella son (Solicitud para la verificación de los Títulos de Grado. Graduado y Graduada en Educación Primaria, 2010, pp. 39-45):

- CU2 Conocer y perfeccionar el nivel de usuario en el ámbito de las TIC.

- CB2 Que los estudiantes sepan aplicar sus conocimientos a su trabajo o vocación de una forma profesional y posean las competencias que suelen demostrarse por medio de la elaboración y defensa de argumentos y la resolución de problemas dentro de su área de estudio.

- CE1 Conocer las áreas curriculares de la Educación Primaria, la relación interdisciplinar entre ellas, los criterios de evaluación y el cuerpo de conocimientos didácticos en torno a los procedimientos de enseñanza y aprendizaje respectivos. Asimismo conocer y comprender los contenidos que constituyen estas áreas curriculares y que posibiliten el logro de las competencias básicas en la Educación Primaria.

- CE2 Diseñar, planificar y evaluar procesos de enseñanza y aprendizaje, tanto individualmente como en colaboración con otros docentes y profesionales del centro.

- CE3 Abordar con eficacia situaciones de aprendizaje de lenguas en contextos multiculturales y multilingües. Fomentar la lectura y el comentario crítico de textos de los diversos dominios científicos y culturales contenidos en el currículo escolar. 
- CE11 Conocer y aplicar en las aulas las tecnologías de la información y de la comunicación. Discernir selectivamente la información audiovisual que contribuya a los aprendizajes, a la formación cívica y a la riqueza cultural.

- CM7.2 Adquirir formación literaria.

- CM7.3 Conocer el currículo escolar de las lenguas y la literatura.

- CM7.6 Fomentar la lectura y animar a escribir.

- CM7.10 Desarrollar y evaluar contenidos del currículo mediante recursos didácticos apropiados y promover la adquisición de competencias correspondientes en los estudiantes (en Lenguas).

- CM7.11 Adquirir habilidades de decodificación y análisis crítico del lenguaje audiovisual.

En esta línea, se formulan los objetivos que se pretenden alcanzar con esta práctica:

- Crear una obra contemporánea.

- Fomentar la escritura.

- Iniciar al alumnado en la escritura creativa.

- Fomentar hábitos de lectura y escritura que permitan al alumnado disfrutar de los textos, desarrollar su creatividad e imaginación, expresar los sentimientos y recrear su entorno.

- Conocer la aportación de las TIC a la formación literaria, desde una perspectiva crítica, y desarrollar recursos didácticos que propicien prácticas de enseñanza innovadoras en Literatura.

- Conocer el lenguaje audiovisual, entender el proceso de codificación y descodificación de este medio de comunicación y saber expresar a través de la narrativa que combina la imagen, el sonido y/o la palabra.

- Adquirir destrezas básicas en la utilización de herramientas informáticas para el tratamiento de la imagen y la edición de vídeo, necesarias para su desempeño profesional como docentes.

\subsection{Metodología}

El diseño e implementación de la práctica "Háblame de Córdoba" se realizó a través de las siguientes fases: diseño y planificación por parte de las profesoras responsables de las materias implicadas, elaboración de la narración audiovisual, y, por último, la evaluación del logro de las competencias y la valoración de la experiencia por el alumnado.

La labor docente comenzó con el análisis y elección de las competencias de ambas materias que se adquieren y desarrollan con esta propuesta de trabajo y la concreción de los bloques teóricoprácticos a tratar desde las asignaturas. Para ello, se seleccionó la modalidad de enseñanza-aprendizaje y la estrategia metodológica que propiciaran la consecución de los objetivos y los resultados esperados. Se optó por la lección magistral para abordar los aspectos teóricos necesarios, talleres, desde el ámbito literario y el tecnológico y tutorías personalizadas, como modalidad del proceso de enseñanza-aprendizaje, para la ejecución de la narrativa.

La práctica se llevó a cabo con 113 estudiantes. Para su ejecución, se programó una temporalización de cuatro semanas. En la asignatura de Formación literaria y Literatura infantil se dedicaron 2 horas, de las 4 asignadas semanalmente, a sesiones teóricoprácticas y talleres para la creación de la obra original. En Educación Mediática se utilizaron la totalidad de las horas lectivas, establecidas 3 horas semanales.

El proyecto fue presentado al alumnado en una sesión informativa que contó con la presencia de las docentes implicadas. Con la ayuda de un guion se abordó su descripción atendiendo a:

- Las características del proyecto: elaboración de un texto original, la correspondiente estructura de la narración audiovisual en función del relato y los programas informáticos necesarios para su edición.

- Los aspectos a tener en cuenta para su producción: elementos morfológicos, sintácticos y semánticos del lenguaje audiovisual, recursos lingüísticos propios de los textos narrativos y literarios en general, elección de la voz narrativa y técnicas de creatividad para la construcción del discurso.

- La presentación del instrumento de evaluación y la posterior valoración del alumnado sobre la satisfacción de la experiencia formativa.

Esta práctica se inició con sesiones de carácter magistral en la asignatura de Formación literaria, en las que se abordaron, desde la perspectiva conceptual, la literatura como comunicación, la obra literaria como forma singular de mensaje y el código literario: las figuras retóricas, las modalidades del discurso -especialmente la narración- y los géneros literarios. Además, se trabajó la relación de la literatura con las otras artes: pintura, escultura, música, cine, gastronomía, con los nuevos discursos contemporáneos, con los medios de comunicación y las nuevas tecnologías, su maridaje con la imagen y las posibilidades de internet en conexión con los 
procesos educativos literarios. Los aprendizajes adquiridos formaron el punto de partida para la realización de la actividad.

El alumnado partió de la creación del relato literario original que serviría de base para el análisis y extrapolación a la narrativa audiovisual. Para ello, se diseñaron sesiones para el fomento y la expresión de la creatividad y un taller de escritura creativa que proporcionara al alumnado la sensibilidad, la actitud y las herramientas necesarias para su ejecución. Las clases se dedicaron también al trabajo del alumnado y a la orientación del mismo por parte del docente, y se llevaron a cabo tutorías individualizadas para las tareas de corrección y reescritura.

Por su parte, la materia de Educación Mediática introdujo al alumnado en la alfabetización audiovisual, a través de los fundamentos de la comunicación visual y audiovisual; la imagen y sus tipos; análisis de las imágenes; el lenguaje audiovisual; la imagen, la palabra y el sonido.

Como en todo proceso de edición de una narrativa audiovisual, para la selección de los diversos elementos que forman parte de un guion técnico, se realizaron tutorías personalizadas, en las cuales se efectuó una lectura del texto de manera horizontal y vertical, buscando la esencia de lo que el autor expresaba en cada párrafo. Con su lectura se apeló a la imagen mental que cada persona se forma al leer-oír las palabras, dando lugar a la imagen deseada y que mejor lo mostrara. Sobre la base del relato, se eligió la modalidad de sonido más adecuada y se estudió la pertinencia o no, de la utilización de texto escrito. Cuando el montaje de la narración estuvo iniciado, se realizaron sesiones para su análisis, que proporcionaron al alumnado la formación adecuada a sus necesidades.

\subsection{Valoración de Háblame de Córdoba}

Como se ha comentado con anterioridad, el sistema de valoración de esta experiencia se realizó, por parte del profesorado, mediante una lista de control como instrumento de evaluación del logro de las competencias y se implementó un cuestionario de satisfacción al alumnado, que proporcionara información para posibilitar el análisis de la eficacia educativa y la mejora de la práctica.

\subsubsection{Evaluación de los aprendizajes del alumnado}

El instrumento de evaluación del logro de competencias lo conformaban los diversos aspectos que se habían trabajado tanto en las sesiones teóricas y los talleres prácticos, como en las tutorías para el seguimiento de la elaboración del producto, que se mantuvieron para facilitar la adquisición y el desarrollo de las competencias que se movilizan con la realización del proyecto (véase tabla 1).

Tabla 1. Criterios de evaluación de la narración audiovisual.

El título es sugerente, motivador y
apropiado.




\begin{tabular}{ll}
\hline Aspectos & \multicolumn{1}{c}{ Criterios } \\
\hline & y el texto utilizado (en el caso de ser \\
utilizado el texto). & El texto tiene su espacio y forma parte de \\
la composición visual (ver y leer & correctamente, en el caso de ser \\
& utilizado). \\
& Se evidencia una relación entre la imagen \\
& y el elemento sonoro utilizado \\
& La calidad del sonido es buena. \\
& El volumen del sonido es bueno. \\
& El proceso de traducir ideas en una forma \\
de expresión mediática (imagen-sonido- & palabra) evidencia síntesis, creatividad y \\
pensamiento crítico.
\end{tabular}

La evaluación del trabajo del alumnado se realizó de manera conjunta entre las docentes de ambas materias. El total de estudiantes que superaron la práctica en primera convocatoria fue del $84 \%$, suspendieron el $8 \%$ y otro $8 \%$ no la presentó. Publicadas las calificaciones, se mantuvieron tutorías con el alumnado suspenso, en las que se analizaron los fallos y se acordaron las mejoras que debían realizar para su presentación en la posterior convocatoria de ambas materias.

\subsubsection{Satisfacción del alumnado con la experiencia}

Para recabar la valoración del alumnado sobre la experiencia, se diseñó un cuestionario ad hoc, en el que se conjugaron variables de tipo cuantitativo y cualitativo, relativas a la ayuda que facilita la realización del proyecto para la adquisición de las competencias de cada materia y sobre el plan de trabajo. En él se abordaron aspectos concernientes a la opinión sobre la coordinación, la metodología, mejoras de la experiencia en estos aspectos, acerca de la satisfacción del alumnado con la labor realizada y a su participación. Este quedó conformado de la siguiente manera:

- Sobre las competencias, definido por dos conjuntos de ítems, 7 relativos a Educación mediática y aplicaciones didácticas de las TIC y 5 a Formación literaria y Literatura infantil, con opciones de respuesta de escala Likert, cuyos valores oscilaban del 1 (totalmente en desacuerdo) a 4 (totalmente de acuerdo).

- Sobre el plan de trabajo, constituido por 13 ítems, de los cuales 11 eran preguntas cerradas de escala Likert con la opción de respuesta formulada en la misma línea que la anteriores y 2 ítems de pregunta abierta, en la que se le solicitaba al alumnado que indicara mejoras en la metodología y, por su parte, aspectos positivos y mejorables de su implicación.

Implementado el instrumento, se procedió al tratamiento de los datos con carácter descriptivo. En primer lugar, se realizó un estudio de consistencia interna, de manera confirmatoria, mediante el coeficiente de fiabilidad, obteniendo un valor total Alfa de Cronbach de 0.810 ( $\mathrm{N}$ elementos=23), lo que indicó una correlación alta y, en consecuencia, un nivel de estabilidad en las respuestas.

Con respecto al bloque de competencias que el alumnado debe adquirir y desarrollar con la elaboración de esta práctica, los resultados arrojaron valores por encima de la media en todas ellas (ver tabla 2):

- Las competencias que consideran que más se han potenciado son las que hacen referencia al fomento de la lectura y escritura (CM7.6) y la que les permite conocer las TIC y discernir la información más relevante para la formación de su futuro alumnado (CE11).

- Cabe señalar que el alumnado también estima de manera muy positiva el grupo de competencias que refleja la capacidad para adquirir formación literaria (CM7.2) y para abordar con eficacia situaciones de aprendizaje de lenguas en contextos multiculturales y multilingües. Fomentar la lectura y el comentario crítico de textos de los diversos dominios científicos y culturales contenidos en el currículo escolar (CE3), así como, la que le capacita para descodificar y realizar un análisis crítico del lenguaje audiovisual (CM7.11).

- Sin embargo, son más críticos con aquellas competencias que aluden al conocimiento y comprensión de los contenidos que constituyen las áreas curriculares y que posibiliten el logro de las competencias básicas en la Educación Primaria (CE1), que sepan aplicar sus conocimientos a su trabajo o vocación de una forma profesional y posean las competencias que suelen demostrarse por medio de la elaboración y defensa de argumentos y la resolución de problemas dentro de su área de estudio (CB2) y que sean capaces de desarrollar y evaluar 
contenidos del currículo mediante recursos didácticos apropiados y promover la adquisición de competencias correspondientes en los estudiantes (en Lenguas) (CM7.10).

Tabla 2. Estadísticos descriptivos básicos del ámbito sobre las competencias.

\begin{tabular}{cccc}
\hline COMPETENCIAS & Media & D.T. & N \\
\hline CU2 & 3.38 & .948 & 113 \\
CB2 & 3.13 & .412 & 113 \\
CE1 & 2.96 & .618 & 113 \\
CE2 & 3.31 & .955 & 113 \\
CE3 & 3.54 & 1.604 & 113 \\
CE11 & 3.67 & 1.572 & 113 \\
CM7.2 & 3.56 & 1.614 & 113 \\
CM7.3 & 3.34 & 1.662 & 113 \\
CM7.6 & 3.73 & 1.588 & 113 \\
CM7.10 & 3.13 & .543 & 113 \\
CM7.11 & 3.44 & 1.069 & 113 \\
\hline
\end{tabular}

El análisis de los resultados obtenidos, de los diversos aspectos sobre el plan de trabajo, pone de manifiesto que las estrategias metodológicas diseñadas han sido satisfactorias para la formación del alumnado, ostentado todas ellas valores por encima de 3 (ver tabla 3):

- Destaca la acogida que le da el alumnado al conocimiento y utilización de este tipo de proyectos para valorar sus logros como alternativa al tradicional examen, $y$ manifiestan un alto grado de satisfacción con el trabajo realizado.

- Por otro lado, para los y las estudiantes son importantes las sesiones dedicadas a la explicación del trabajo que se les requería y las tutorías de seguimiento de su consecución. En igual medida consideran que tener un guion de la práctica les orienta a la hora de saber qué competencias movilizan.

- Los resultados concernientes a los talleres que se imparten desde ambas materias, evidencian la eficacia de los mismos para la realización de la práctica solicitada, siendo sus valores muy similares.

- Llama la atención que el aspecto que refleja menor valoración sea el que hace referencia a las horas lectivas que se dedican a la elaboración del proyecto.

Tabla 3. Estadísticos descriptivos básicos del ámbito sobre el plan de trabajo.

\begin{tabular}{lccc}
\hline & Media & D.T. & N \\
\hline $\begin{array}{l}\text { La sesión de clase dedicada a la presentación del proyecto me ha servido para entender qué } \\
\text { tenía que hacer. }\end{array}$ & 3.26 & .496 & 113 \\
$\begin{array}{l}\text { El guion me ha servido para saber qué tenía que hacer y qué competencias se han trabajado } \\
\text { de cada materia. }\end{array}$ & 3.26 & .514 & 113 \\
$\begin{array}{l}\text { Las horas de clase presencial para trabajar me han servido para poder avanzar en la } \\
\text { ejecución del proyecto. }\end{array}$ & 3.04 & .603 & 113 \\
$\begin{array}{l}\text { El taller de escritura me ha servido para llevar a cabo la tarea solicitada. } \\
\text { Las tareas de reescritura me han servido para llevar a cabo la tarea solicitada. }\end{array}$ & 3.19 & 1.130 & 113 \\
$\begin{array}{l}\text { El taller de tratamiento de la imagen me ha servido para llevar a cabo la tarea solicitada. } \\
\text { El taller de edición de vídeo me ha servido para llevar a cabo la tarea solicitada. }\end{array}$ & 3.13 & .867 & 113 \\
Las tutorías de seguimiento (individual o grupal), han servido para mi aprendizaje. & 3.17 & .611 & 113 \\
Conocer los indicadores con los que voy a ser evaluado (lista de control) han servido para & 3.26 & .864 & 113 \\
guiar mi trabajo y mejorar mi aprendizaje. & 3.19 & .497 & 113 \\
Conocer y utilizar alternativas de evaluación diferentes al examen tradicional han & 3.32 & .816 & 113 \\
contribuido a formarme como maestro/a. & 3.32 & .587 & 113 \\
En general, estoy satisfecho/satisfecha con el trabajo que he realizado en esta práctica. & &
\end{tabular}

Por otro lado, se solicitó al alumnado que indicara las mejoras que considerara con respecto a la metodología, en el caso de que así lo estimara. Del total de alumnos y alumnas encuestados, solo 11 realizaron comentarios, siendo el aspecto más repetido la necesidad de ampliar el tiempo de tutorías de seguimiento de la práctica. También cabe mencionar las recomendaciones dadas sobre la limitación del peso del archivo generado.

Además, se indicó que se señalasen al menos dos aspectos positivos y dos mejorables de su participación. A este apartado, contestaron 32 estudiantes y destacaron como positivo:

- La motivación que les produjo escribir un texto original y realizar sus propias fotografías. Esta práctica ha supuesto una vía para poder expresar sus vivencias, sentimientos de manera libre, tal y como ellos y ellas ven su ciudad, descubriendo el potencial que tienen para comunicar y ser creativos. 
- La entrega que han tenido en este proyecto, al considerarlo una forma innovadora de aprender y demostrar el resultado de su aprendizaje de manera personalizada.

- La soltura que han adquirido y experimentado para crear un proyecto original.

Por su parte, los aspectos negativos mencionados en su mayoría hacen alusión a:

- La falta de organización a la hora de planificarse el trabajo, no recurriendo en más ocasiones a las tutorías de seguimiento, dejando el grueso del trabajo para el final.

- El sentido del ridículo y la vergüenza que han sentido al mostrar en un texto escrito su manera de ver y sentir, al igual que al narrar oralmente, con su propia voz, transmitiendo en la dicción/entonación sus emociones.

- Las carencias de formación, de expresión, etc. que han detectado para ser creativos, originales y salir de lo convencional.

\section{CONCLUSIONES}

A partir del logro de los objetivos formulados, los resultados de aprendizajes obtenidos y la satisfacción manifestados por el alumnado con esta experiencia, se evidencia la eficacia de las actividades académicamente dirigidas, en las cuales el alumnado toma el protagonismo del acto formativo y se responsabiliza de su propio trabajo, siendo el docente un mero guía y acompañante de su aprendizaje. Esto conlleva, para los estudiantes, un alto grado de satisfacción por el trabajo realizado.

Se valoran positivamente también los escenarios formativos flexibles, adaptados a las necesidades de formación del alumnado que facilitan las metodológicas emergentes.

Por su parte, la apreciación del alumnado pone de manifiesto que la coordinación entre los docentes de distintas áreas les permite tener una visión de conjunto de la finalidad y funcionalidad de las competencias que definen el plan de estudios de la titulación que cursan, fomenta en ellos la movilización de los aprendizajes en contextos diferentes de la propia materia en la que se inscriben, tal y como persigue la filosofía de los Grados, lejos del concepto tradicional de asignatura estanco.

El carácter individual y creativo de la práctica se aprecia como un inconveniente en cuanto al tiempo que este proceso requiere. La labor de escritura y reescritura, así como el análisis del relato para modular la narrativa audiovisual demanda la adquisición y el desarrollo de unas habilidades que conllevan una fase madurativa de las ideas y la puesta en práctica de los aprendizajes necesarios para saber expresarse en estos lenguajes. A su vez, el número de alumnos y alumnas, que forman los grupos, impide que los docentes puedan tener más de dos o tres reuniones de asesoramiento con cada uno, lo que les condiciona, en cierta manera, la elaboración y motivación por la misma. Ello se agrava sobre todo al coincidir en el tiempo, la mayoría de las demandas de asesoramiento, complicación que no se consiguió subsanar con la ampliación de las tutorías fuera del tiempo lectivo.

Por último, con respecto al desarrollo de las competencias trasversales comunicativa y digital, a través de "Háblame de Córdoba" el alumnado ha podido acercarse, entre otras, al dominio de la palabra, al uso de las figuras retóricas y las modalidades del discurso, al análisis de la imagen, discriminando cuándo esta es utilizada para informar de cuándo tiene una mera función ilustrativa o de acompañamiento de la información, a la importancia del sonido para crear situaciones o predisponer al destinatario, al desarrollo, desde la obra original y creativa, de su capacidad expresiva favoreciendo, con ello, uno de los factores más importantes en su futuro profesional, saber comunicar.

\section{REFERENCIAS}

Álvarez, M. (2008). La tutoría académica en el espacio europeo de la Educación Superior. Revista Interuniversitaria de Formación del Profesorado, 22(1), 71-88. Recuperado https://dialnet.unirioja.es/ejemplar/183712

Canale, M. (1995). De la competencia comunicativa a la pedagogía comunicativa del lenguaje. En Llobera, M. (Ed), Competencia comunicativa. Documentos básicos en la enseñanza de lenguas extranjeras (pp. 63-82). Madrid: Edelsa.

Fernández, A. (2010). La evaluación orientada al aprendizaje en un modelo de formación por competencias en la educación universitaria. Revista de Docencia Universitaria, 8(1), 11-34. Recuperado de http://redu.net/redu/index.php/REDU/article/view/144

Ferrés, J. (2007). La competencia en comunicación audiovisual: dimensiones e indicadores. Revista Científica de Comunicación y Educación: Comunicar, 25(29), 100$107 . \quad$ Recuperado de http://rabida.uhu.es/dspace/bitstream/handle/10272/13 48/b15282272.pdf?sequence $=1$

Gómez, Isla, J. (2013). Arte, documento y discurso audiovisual: entre la imagen de la ciencia y la ciencia de la imagen. Salamanca: Universidad de Salamanca.

Gómez, Tarín, F. J. (2011). Elementos de narrativa audiovisual. Expresión y narración. Santander: Shangrila Ediciones.

Gumperz, J. y Hymes, D. (1972). Directions in Sociolinguistics. The Etnography of Communication. Nueva York: Holt, Rinehart and Winston. 
Imaz, J. I. (2015). Aprendizaje Basado en Proyectos en los grados de Pedagogía y Educación Social: “¿Cómo ha cambiado tu ciudad?". Revista Complutense de Educación, 26(3), 679-696. Recuperado de https://revistas.ucm.es/index.php/RCED/article/view/4 4665

Ley Orgánica 8/2013, de 9 de diciembre, para la mejora de la calidad educativa, 295, BOE, 10 de diciembre de $2013 . \quad$ Recuperado de http://www.boe.es/boe/dias/2013/12/10/pdfs/BOE-A2013-12886.pdf

Lomas, C. (2010). Cómo enseñar a hacer cosas con palabras. Teoría práctica de la educación lingüística. Barcelona: Paidós.

Mayorga, M. J. y Madrid, D. (2010). Modelos didácticos y Estrategias de enseñanza en el Espacio Europeo de Educación Superior. Revista Tendencias pedagógicas, 1(15), 91-111. Recuperado de http://www.tendenciaspedagogicas.com/Articulos/201 0_15_04.pdf

Mendoza, A. (2008). Didáctica de la lengua y la literatura para Primaria. Madrid: Prentice Hall.

Muñoz, J. J. (2003). Cine y el misterio humano. Madrid: Rialp

Orden de 17 de marzo de 2015, por la que se desarrolla el currículo correspondiente a la Educación Primaria en Andalucía, 60, BOJA, 27 de marzo de 2015. Recuperado http://www.juntadeandalucia.es/boja/2015/60/BOJA15 -060-00134-5243-01_00066439.pdf

Pérez, M. A. y Delgado, A. (2012). De la competencia digital y audiovisual a la competencia mediática: dimensiones e indicadores. Comunicar, 39, 25-34. Recuperado de http://www.revistacomunicar.com/pdf/comunicar39.pd $\mathrm{f}$

Prado, J. (2001). La competencia comunicativa en el entorno tecnológico: desafío para la enseñanza. Comunicar, 17, 21-30. Recuperado de http://www.redalyc.org/articulo.oa?id=15801704

Real Decreto 126/2014, de 28 de febrero, por el que se establece el currículo básico de la Educación Primaria, 52, BOE, 1 de marzo de 2014. Recuperado de https://www.boe.es/boe/dias/2014/03/01/pdfs/BOE-A2014-2222.pdf

Rodríguez, J. L. (2004). Las alfabetizaciones digitales. Bordón, $56,431-441$.

Solicitud para la verificación de los Títulos Oficiales de Grado. (2010). Graduado y Graduada en Educación Primaria por la Universidad de Córdoba. Recuperado de http://www.uco.es/sagradocorazon/principal/verifica/d ocumentos/grado\%20primaria/FormularioSolicitudVer ificaEP.pdf

Vázquez, J. A. (2015). Nuevos escenarios y tendencias universitarias. Revista de Investigación Educativa, 33(1), pp. 13-26. http://dx.doi.org/10.6018/rie.33.1.211501 